\title{
Influence of Temperature on Structural, Functional and Morphological Properties of Ag[PVP] Nanoparticles and Their Biological Applications
}

\author{
I. Kartharinal Punithavathy', P. Jamila Jayanthi1,*, S. Johnson Jeyakumar ${ }^{1}$, T. Elavazhagan ${ }^{2}$ \\ ${ }^{1} P G$ \& Research Department of Physics, T.B.M.L College, Porayar - 609 307, Tamilnadu, India. \\ ${ }^{2}$ Department of Biotechnology, Research and Development Centre, Bharathiyar University, Coimbatore - 641 046, Tamilnadu, India.
}

\section{ART ICLEDETAILS}

\section{Article history:}

Received 22 May 2019

Accepted 07 June 2019

Available online 13 June 2019

Keywords:

Silver Nanoparticles

PVP

Antibacterial Studies

\begin{abstract}
A B S T R A C T
The present work was undertaken to develop silver nanoparticles by a simple chemical route using harmless surfactant polyvinylpyrrolidone (PVP) at four different temperatures viz., $200{ }^{\circ} \mathrm{C}, 300^{\circ} \mathrm{C}, 400$ ${ }^{\circ} \mathrm{C}$ and $500{ }^{\circ} \mathrm{C}$. Effect of temperature on structural, morphological and antibacterial properties was investigated. The XRD pattern confirmed the crystallinity and pure phase of the Ag-NPs. Also it is confirmed that the size of the Ag[PVP] nanoparticles was affected by the temperature. The FT-IR analysis indicated the functional groups of PVP coordinate with silver ions and bind on surface of Ag-NPs. EDAX confirmed the formation of Ag nanoparticles without a trace of impurities. The SEM images showed the formation of spherical Ag[PVP] nanopowder in which the average particle size ranges from $20 \mathrm{~nm}$ to 34 $\mathrm{nm}$. The antibacterial potential of synthesized Ag[PVP] nanoparticles was carried out against four different bacterial pathogens and show significant bacterial resistance.
\end{abstract}

\section{Introduction}

Nowadays nanotechnology has been embraced by industrial sectors due to its broad range applications in the field of electronic storage systems [1] biotechnology [2], medical science and tool for gene and drug delivery systems [3-6]. Metallic nanoparticles demonstrate size and shape-dependent properties that are of interest for applications ranging from catalysts and sensing to optics, antimicrobial activity. As the field of nanotechnology advanced, metallic nanoparticles become apparent having different properties as compared to their larger counterparts. This difference in the physical and chemical properties of nanomaterials can be attributed to their high surface-to-volume ratio. Due to these unique properties, they make excellent candidate for biomedical applications as variety of biological processes occur at nanometer scales [7]. Silver ions and silver-based compounds have been used as antimicrobial agents in biomedicine for many years because of their broad-spectrum bactericidal activity and lower bacterial resistance than antibiotics. Silver nanoparticles are a typical representative of the new generation of bactericidal materials.

As the properties of Ag-NPs depend on their sizes, up to now, various methods, such as polyol process [8,9], microwave assisted [10,11], UV irradiation [12], laser irradiation [13], wet chemical route [14], spray pyrolysis [15], sol-gel process [16], chemical reduction [17], sonochemical [18], sputtering [19], in such manner, have been employed to prepare AgNPs with different sizes and shapes. Among the various methods for synthesis of Ag-NPs, the chemical reduction method is the most popular synthesis route, simple, easy to handle, cost effective and large-scale production of Ag-NPs.

The use of appropriate stabilizers for the Ag-NPs, changing the permeability of bacterial cell walls, increases the penetrating power of the Ag-NPs, in that way contributing appreciably to enhance the antibacterial ability of the nanoparticles [10]. PVP has been utilized while preparing silver nanoparticles. These nanoparticles can disperse easily in PVP which in turn can act as protective layer around Ag-NPs preventing the aggregation that may occur [20]. Utilize of dispersant has to create complex compound with the metal precursor, control the reaction process and to protect nanoparticles from growth and agglomeration [14].
In this study, we explore the influence of temperature on PVP coated silver nanopowder via simple chemical reduction at different temperatures viz., $200{ }^{\circ} \mathrm{C}, 300{ }^{\circ} \mathrm{C}, 400{ }^{\circ} \mathrm{C}$ and $500{ }^{\circ} \mathrm{C}$ using dextrose as reducing agent. We have investigated effect of temperature on structural, morphological properties of $\mathrm{Ag}[\mathrm{PVP}]$ nanoparticles and antibacterial potential on different human pathogens..

\section{Experimental Methods}

\subsection{Reagents}

Silver nitrate $\left(\mathrm{AgNO}_{3}, \mathrm{M} . \mathrm{W} .169 .87 \mathrm{~g} / \mathrm{mol}, 99.99 \%\right)$, dextrose and $\mathrm{NaOH}$ were used as precursor, reducing agent and catalyst respectively and were purchased from Merck. Poly(N-vinylpyrrolidone (PVP, M.W. $40000 \mathrm{~g} / \mathrm{mol}$ ) used as a stabilizer was purchased from Loba Chem. Deionized water was used throughout the study.

\subsection{Preparation of Silver Nanoparticles}

Silver nitrate solution was prepared by adding $0.1 \mathrm{M}$ of $\mathrm{AgNO}_{3}$ (metal precursor) into $10 \mathrm{~mL}$ deionized water. Dissolving $0.006 \mathrm{M}$ of PVP, $6 \mathrm{~g}$ of dextrose and $1 \mathrm{~g}$ of $\mathrm{NaOH}$ in $30 \mathrm{~mL}$ deionized water together and heated to $60{ }^{\circ} \mathrm{C}$ and stirred hardly then $\mathrm{AgNO}_{3}$ solution was added drop wise into PVP mixer. When the complete amount of silver nitrate solution was added, the reaction mixture was stirred for 20 min with constant temperature. The black precipitates were separated by centrifugation and washed with deionized water many times and particles were incubated at $80{ }^{\circ} \mathrm{C}$ till the wetness may well be removed. Black solids of Ag-NPs were collected and crushed with uniform Ag-NPs using mortar. The powder was heated in a muffle furnace at $200{ }^{\circ} \mathrm{C}$ for $1 \mathrm{~h}$ to get the Ag[PVP] nanopowder. Similar procedure has been repeated for different temperatures such as $300^{\circ} \mathrm{C}, 400{ }^{\circ} \mathrm{C}$ and $500{ }^{\circ} \mathrm{C}$.

\subsection{Antibacterial Activity - Disc Diffusion Method}

The four different test organisms used in this present study were Escherichia coli, Pseudomonas aeruginosa, Staphylococcus aureus and Bacillus subtilis. The whole test cultures were verified before use. The test cultures were maintained at $4{ }^{\circ} \mathrm{C}$ on Nutrient agar (HiMedia) slants. The bacterial resistance activity of the chosen sample preparations was carried out by agar disc diffusion technique. $20 \mathrm{~mL}$ of sterile Muller Hinton agar (Hi Media) was poured in sterile petri dishes. The petriplates were allowed to coagulate and used. $10 \mathrm{~mL}$ of sterile, Muller Hinton agar medium was 
seeded with test organism (about $0.2 \mathrm{~mL}$ according to $0.5 \mathrm{McF}$ arland's standard), in semi hot conditions and was poured evenly on the base agar. Standard sterile disc was inoculated with $100 \mu \mathrm{L}$ of the various sample preparations were added to respectively and it was repeated for three times. These sampled discs were located within the plate. The petriplates were incubated at $37 \pm 1{ }^{\circ} \mathrm{C}$ for $24 \mathrm{hr}$ and the diameter of inhibition zone was measured using antibiotic zone reader.

\subsection{Characterizations of the Particles}

Characterization of the Ag[PVP] nanoparticles were achieved by various techniques. The crystal phase and structure of the nanoparticles were characterized by X-ray powder diffraction (SHIMADZU-XRD 6000) analysis. The morphologies of the Ag[PVP] nanoparticles were observed by scanning electron microscopy (Hitachi S-4500 SEM Machine). Fourier transform infrared (FT-IR) spectra were recorded in the range 4000-500 $\mathrm{cm}^{-1}$ using a BRUKER: RFS 27.

\section{Results and Discussion}

\subsection{X-Ray Diffraction (XRD)}

Fig. 1 shows the X-ray diffraction patterns of Ag[PVP] nanoparticles formed in different temperatures which indicate the formation of the

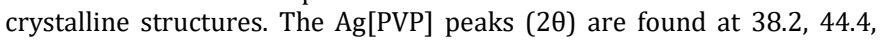

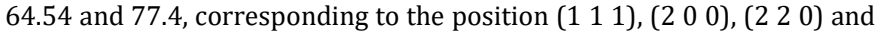
(3 11 1). All the peaks of X-ray diffraction patterns can be readily indexed to FCC phase of the silver (JCPDS file No: 04-0783) [21-25]. The high intense peak for face-centered cubic materials is usually (1 111 ) crystalline plane and it is observed in the sample.

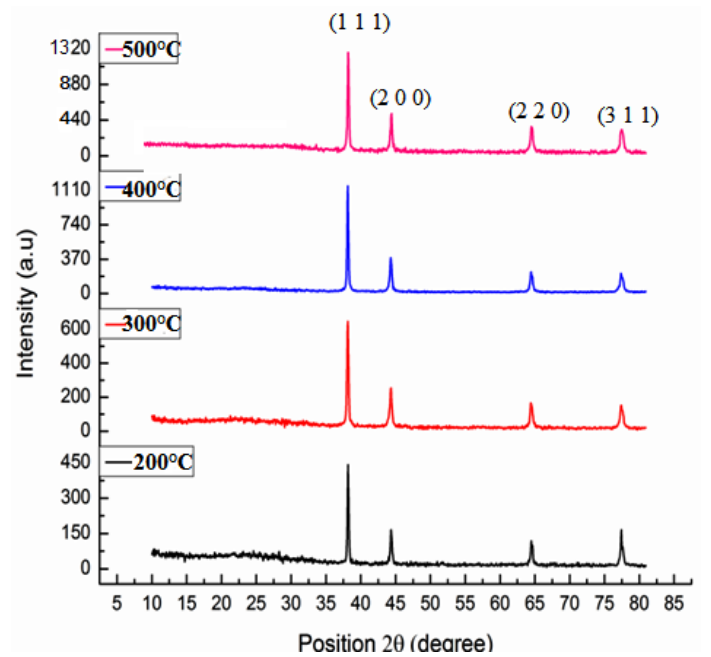

Fig. 1 XRD pattern of $\mathrm{Ag}[\mathrm{PVP}]$ nanopowder at different temperatures

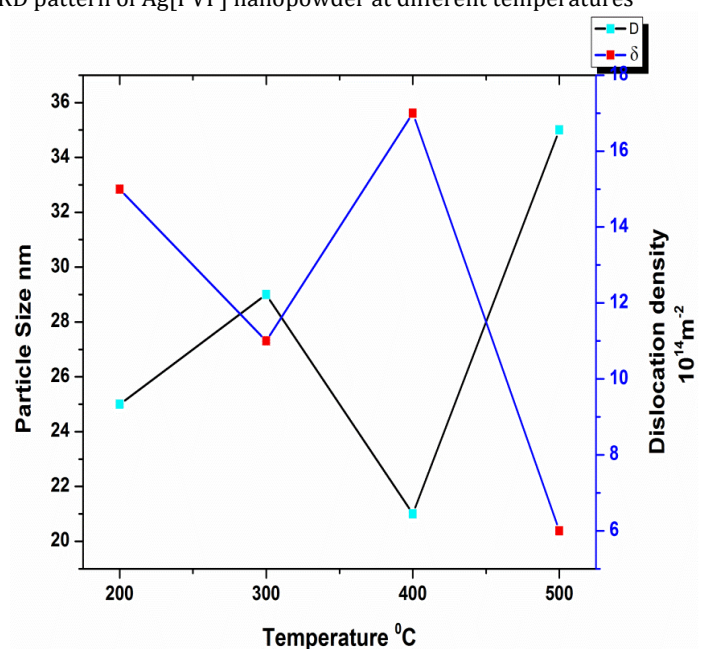

Fig. 2 Relation between crystallite size and dislocation density of Ag[PVP] nanoparticles for various temperatures

The maximum intensity peaks reflect the crystallinity of the highly pure silver nanoparticles. The increase of strain causes the increase of lattice constants and reduction in the crystal size (Fig. 2) Ag[PVP] with larger size appeared with lower temperature $\left(200{ }^{\circ} \mathrm{C}\right.$ and $\left.300{ }^{\circ} \mathrm{C}\right)$ because of nucleation and growth of PVP on the surface of silver nanoparticles. https://doi.org/10.30799/jnst.265.19050417
Therefore, Ag-NPs had a larger particle size of about $25 \mathrm{~nm}-29 \mathrm{~nm}$. With increasing temperature at $400{ }^{\circ} \mathrm{C}$, a greater number of Ag-NPs were covered by the PVP molecules due to increasing the surface binding of capping agent and decreasing the crystallite size is about $21.2 \mathrm{~nm}$. By raising the temperature at $500{ }^{\circ} \mathrm{C}$, the PVP layer becomes decomposed and mean size of silver nanoparticles becomes larger than Ag nanoparticles protected with PVP at lower temperatures [2]. Silver nanoparticles starts to grow after smaller Ag-NPs agglomerated in to larger particles when PVP was removed [1].

Therefore, this gives clear evidence that PVP enhance the stability and size control of Ag-NPs (Fig. 3). The average crystallite size of the nanocrystals was calculated after appropriate background correction from X-ray line broadening of the diffraction peaks of $\left(\begin{array}{lll}1 & 1 & 1\end{array}\right)$ plane using Debye Scherer's formula [26],

$$
\text { The crystallite size (D) }=\frac{0.94 \lambda}{\beta \cos \theta}
$$

Where $\lambda$ is the wavelength of X-ray used (1.5406 $\AA$ ), $\beta$ is the full width at half maximum (FWHM) in radians along ( $\left.\begin{array}{lll}1 & 1 & 1\end{array}\right)$ plane and $\theta$ is Bragg's diffraction angle in degrees.

The micro-strain $(\varepsilon)$ can be determined by the formula [27]

$$
\varepsilon=\frac{\beta \cos \theta}{4}
$$

The dislocation density $(\delta)$ [28] and stacking fault (SF) [29] were determined using the following relations,

$$
\begin{aligned}
& \delta=\frac{1}{\mathrm{D}^{2}} \\
& S F=\left[\frac{2 \pi^{2}}{45(3 \tan \theta)^{\frac{1}{2}}}\right] \beta
\end{aligned}
$$

The structural parameters including dislocation density $(\delta)$, micro strain $(\varepsilon)$, stacking fault (SF) of Ag [PVP] nanoparticles are summarized in Table 1 . The average crystallite size of Ag [PVP] nanoparticles at various temperature of $200{ }^{\circ} \mathrm{C}, 300^{\circ} \mathrm{C}, 400^{\circ} \mathrm{C}$ and $500{ }^{\circ} \mathrm{C}$ are about $25.36,29.57$ 21.2 and $35.54 \mathrm{~nm}$. The smallest particle size was obtained at temperature of $400{ }^{\circ} \mathrm{C}$. These results are good agreement with SEM results Fig. 5 .

Table 1 Structural parameters of Ag[PVP] nanoparticles with various temparatures

\begin{tabular}{lllll}
\hline $\begin{array}{l}\text { Temperature } \\
{ }^{\circ} \mathrm{C}\end{array}$ & $\begin{array}{l}\text { Crystallite size } \\
\text { D nm }\end{array}$ & $\begin{array}{l}\text { Dislocation } \\
\text { density } \delta \mathrm{x} \\
10^{14} \mathrm{~m}^{-2}\end{array}$ & $\begin{array}{l}\text { Micro } \\
\text { strain } \\
\text { E }\end{array}$ & $\begin{array}{l}\text { Stacking } \\
\text { Fault }\end{array}$ \\
\hline 200 & 25.36 & 15.54 & 0.0014 & 0.0022 \\
300 & 29.57 & 11.43 & 0.0012 & 0.0024 \\
400 & 21.2 & 17.57 & 0.0015 & 0.0018 \\
500 & 35.54 & 6.10 & 0.0008 & 0.0026 \\
\hline
\end{tabular}

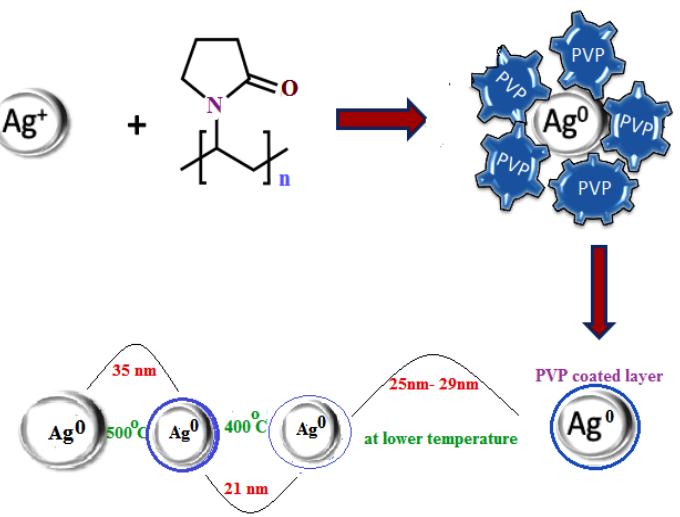

Fig. 3 Mechanism of interactions between PVP and silver ions in the formation of $\mathrm{Ag}[\mathrm{PVP}] \mathrm{NPs}$ at various temperatures

\subsection{FT-IR Analysis}

FT-IR analysis was carried out to identify the coordination between silver nanoparticles and PVP molecules at various temperatures. Figs. $4 a$ and $b$ shows the FT-IR spectra of pure PVP and Ag[PVP] at various temperatures respectively. From this study we confirmed that the surfactant acts a twin role of stabilization and formation of silver nanoparticles. During the reaction, PVP stabilized silver nitrate by means of amide group steric and electrostatic stabilization [30-32]. In PVP spectra, the absorption peak locates at around $1654 \mathrm{~cm}^{-1}$ and $1274 \mathrm{~cm}^{-1}$ are attributed to the functional groups $(\mathrm{C}=\mathrm{O}$ and $\mathrm{C}-\mathrm{N})$ of PVP. Fig. 4 shows 
the FT-IR spectra of the Ag [PVP] NPs for different temperatures. The peaks 3445, 2881, 2378, 1674, 1384 and $1288 \mathrm{~cm}^{-1}$, which are attributed to the covalent bond's vibration of $\mathrm{O}-\mathrm{H}$ stretching, $\mathrm{C}-\mathrm{H}, \mathrm{CH}_{2}, \mathrm{C}=\mathrm{O}, \mathrm{C}-\mathrm{N}$ stretching, $\mathrm{C}-\mathrm{C}$ and Ag-O bonding. The major shift was observed in the carbonyl, hydroxyl and amino groups present. It may be due to coat covering PVP, present in the Ag-NPs region. The peak $880 \mathrm{~cm}^{-1}$ assigns that the vibration of the pyrrolidone ring [33, 34]. The bond $424 \mathrm{~cm}^{-1}$ corresponds to the ionic bond groups vibration of Ag-O bonding [35, 36]. The vibrational spectra of Ag nanoparticles were not observed sharp absorption peak at any wave numbers during at $500{ }^{\circ} \mathrm{C}$ because of PVP decomposing. This indication implies that by increasing temperatures, high purity Ag-NPs have been obtained (Fig. 4).
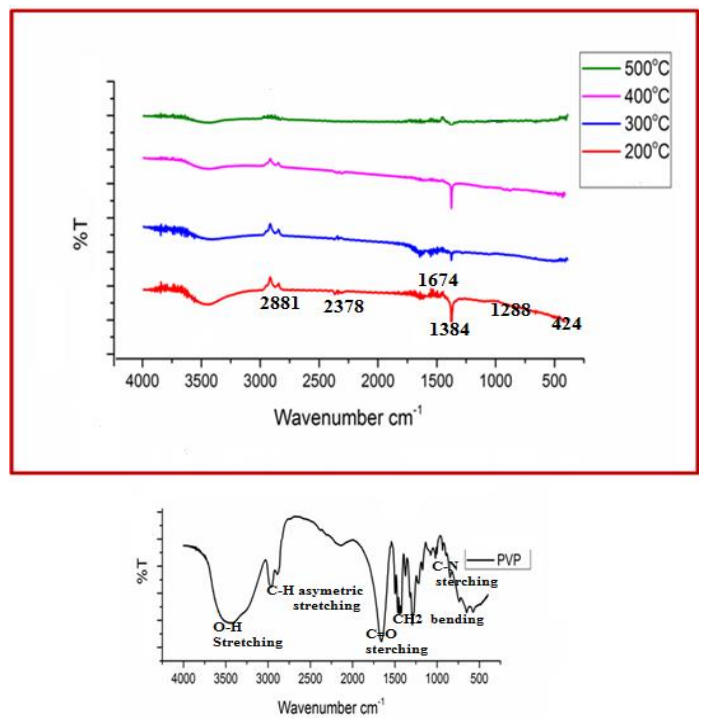

Fig. 4 FT-IR spectrum for Ag [PVP] at different temperatures and pure PVP alone

\subsection{SEM Analysis}

It can be seen that the particle shape and degree of aggregation distinctly depend on surfactant and temperature variation. The distribution of particles narrows down between $20.34 \mathrm{~nm}$ and $34.55 \mathrm{~nm}$ showing that the nucleation of silver nanoparticles can be controlled by the use of protective agent (PVP) at suitable temperature. The morphologies of the particles are in spherical shape (Figs. 5a-d). The role of surfactant for a better surface protection of the Ag-NPs in $400{ }^{\circ} \mathrm{C}$ is therefore optimized (Fig. 5c). By raising the temperature at $500{ }^{\circ} \mathrm{C}$, mean size of silver nanoparticles becomes larger due to decomposition of PVP coating.

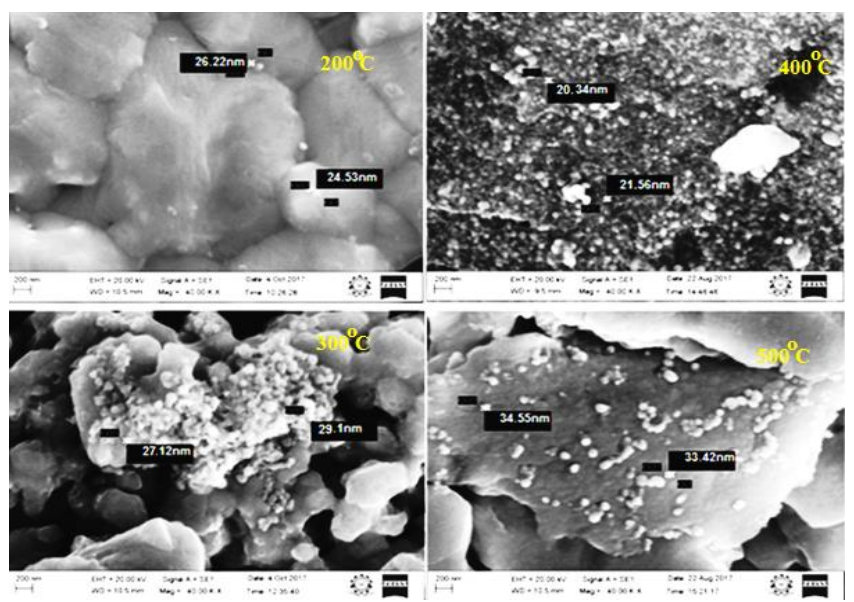

Fig. 5 SEM images of Ag [PVP] NPs at four different temperatures a) $200{ }^{\circ} \mathrm{C}$, b) 300 ${ }^{\circ} \mathrm{C}$ c) $400{ }^{\circ} \mathrm{C}$ and d) $500{ }^{\circ} \mathrm{C}$

\subsection{EDAX Analysis}

To determine further identity of the Ag [PVP] nanoparticles, EDAX analysis were carried out and the spectrum is used to confirm the composition of the nanoparticles. The typical EDAX pattern of PVP capped nanosilver for various temperatures are presented in Fig. 6. The high intensity peak indicates abundance of $\mathrm{Ag}$ nanoparticles. The appearance of $\mathrm{C}$ and $\mathrm{O}$ peaks are due to the mixture of dispersant PVP molecule present on the surface of silver nanoparticles.

https://doi.org/10.30799/jnst.265.19050417

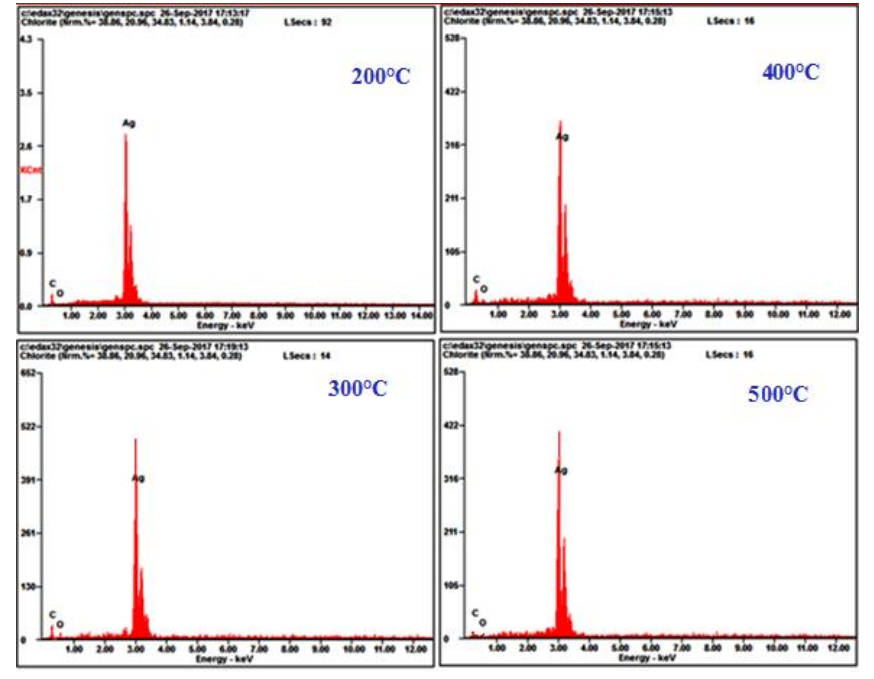

Fig. 6 EDAX Spectrum of silver nanoparticles at four different temperatures

\subsection{Antibacterial Efficacy Studies}

Agar disc diffusion technique $[36,37]$ was used to study the antibacterial potential of Ag [PVP] nanoparticles prepared by simple chemical reduction method with four different temperatures against four various human bacterial strains. The silver compounds were treated against the bacterial strains and the diameter of inhibition zone was measured. The result shows that the Ag [PVP] composite are effective against the tested organisms such as E. coli, S. aureus, P. aeruginosa and $B$. subtilis.
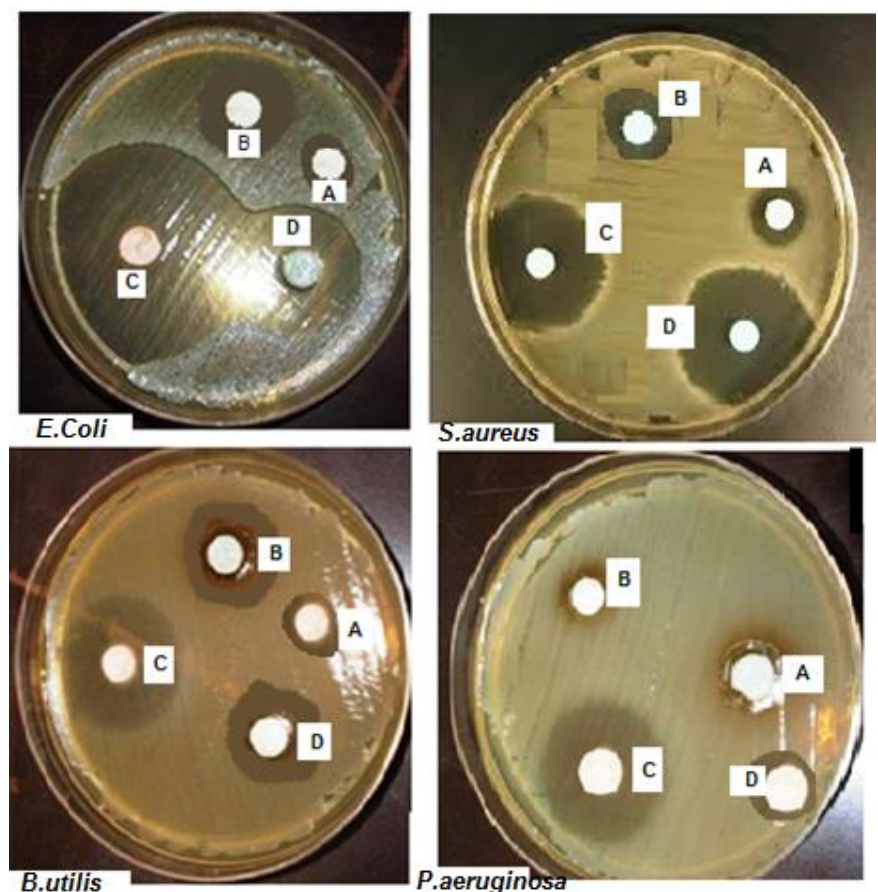

Fig. 7 The diameter of inhibition zone of $\mathrm{Ag}[\mathrm{PVP}]$ nanoparticles in presence of different bacterial pathogens

Fig. 7 illustrates the images of each inhibition zones of different bacterial pathogens for Ag[PVP] synthesized at various temperatures. The diameters of each inhibition zones were measured and the results of the finding are shown in Table 2. The results show that, there was zone of growth inhibition around all the discs tested and compared against the $B$. subtilis E. coli, s. aureus and P. aeruginosa (Fig. 8). This showed that all the as-synthesized Ag-NPs had antibacterial activity against the four different bacteria under study.

The antibacterial activities of Ag nanoparticles capped with PVP at different temperatures were compared and it shows that the activity was more in $400{ }^{\circ} \mathrm{C}$ Table 2 . The maximum zone of inhibition was observed in E. coli $(28 \mathrm{~mm})$ ( Fig. 8). The antibacterial activity of the Ag[PVP] was analyzed with different temperatures and it was found that it can be modified with the size of nanoparticles. The zone of inhibition increases with a decrease of the particle size. 


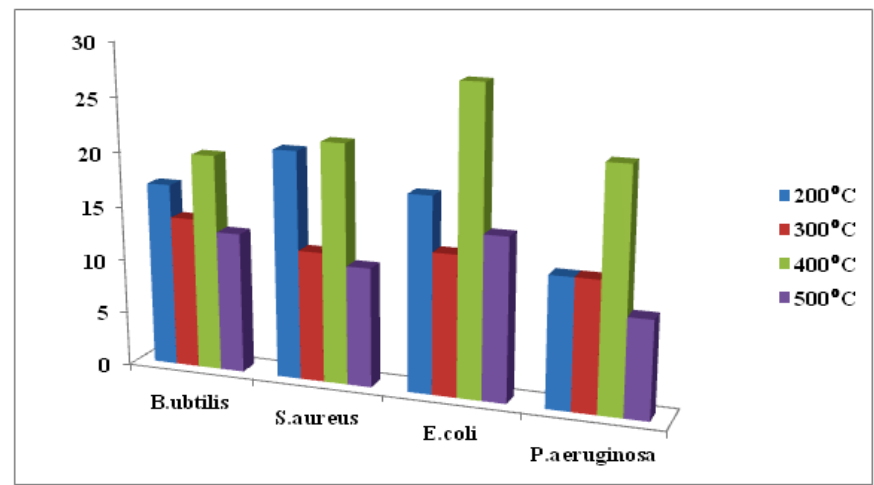

Fig. 8 Comparison of the inhibition zone of $\mathrm{Ag}[\mathrm{PVP}] \mathrm{NPs}$ with different temperatures for various bacterial pathogens

Table 2 Zone of inhibition of Ag[PVP] nanoparticles at different temperatures for various bacterial cultures

\begin{tabular}{llllll}
\hline S. No. & Name of the organisms & \multicolumn{4}{l}{ Zone of inhibition $(\mathrm{mm})$} \\
\cline { 3 - 6 } & & $200{ }^{\circ} \mathrm{C}$ & $300{ }^{\circ} \mathrm{C}$ & $400{ }^{\circ} \mathrm{C}$ & $500{ }^{\circ} \mathrm{C}$ \\
\hline 1 & Bacillus ubtilis & 17 & 14 & 20 & 13 \\
2 & Staphylococcus aureus & 21 & 12 & 22 & 11 \\
3 & Escherichia coli & 18 & 13 & 28 & 15 \\
4 & Pseudomonas aeruginosa & 12 & 12 & 22 & 9 \\
\hline
\end{tabular}

\section{Conclusion}

The present chemical reduction method is a simple, most convenient and cost-effective route to prepare Ag-NPs with narrow size and largescale production. In this study, the influence of PVP on the physical, chemical and biological properties of dextrose reduced silver nanoparticles for different temperatures was investigated. The presence of PVP is most important to synthesize silver nanoparticles. The PVP behaves as a capping and shielding agent in the preparation of $\mathrm{Ag}$ nanoparticles, which passivate the silver atoms and prohibited them from agglomeration. Therefore, by increasing the temperature to $400{ }^{\circ} \mathrm{C}$, more $\mathrm{Ag}$ atoms cap and at the end, the size of the silver nanoparticles was decreased. The optimum temperature that can be used to produce Ag [PVP] nanoparticles with narrow size can be $400{ }^{\circ} \mathrm{C}$. By increasing temperature to $500^{\circ} \mathrm{C}$, high purity Ag-NPs have been obtained due to the decomposition of PVP layer. The antibacterial activity of Ag nanoparticles capped with PVP at different temperatures was compared and it showed that the activity was more in smaller particle size. Strong bacterial resistance is observed against four different bacterial strains of $\mathrm{Ag}[\mathrm{PVP}]$ which could be used as antimicrobial agent in clinical, cosmetics and food industries, etc.

\section{References}

[1] Y.S. Kang, S. Risbud, J.F. Rabolt, P. Stroeve, Synthesis and characterization of nanometer-size $\mathrm{Fe}_{3} \mathrm{O}_{4}$ and $\mathrm{Fe}_{2} \mathrm{O}_{3}$ particles, Chem. Mater. 8 (1996) 2209-2211.

[2] Q.A. Pankhurst, J. Connolly, S.K. Jones, J. Dobson, Applications of magnetic nanoparticles in biomedicine, J. Phys. D Appl. Phys. 36 (2003) 167-181.

[3] J. Dobson, Gene therapy progress and prospects: magnetic nanoparticle-based gene delivery, Gene Ther. 13 (2006) 283-287.

[4] S. Rudge, C. Peterson, C. Vessely, J. Koda, S. Stevens, L. Catterall, Adsorption and desorption of chemotherapeutic drugs from a magnetically targeted carrier (MTC), J. Control Release. 74 (2001) 335-340.

[5] B. Chertok, B.A. Moffat, A.E. David, F. Yu, C. Bergemann, B.D. Ross, Iron oxide nanoparticles as a drug delivery vehicle for MRI monitored magnetic targeting of brain tumors, Biomat. 29 (2008) 487-496.

[6] D.A. Giljohann, D.S. Seferos, W.L. Daniel, M.D. Massich, P.C. Patel, C.A. Mirkin, Gold nanoparticles for biology and medicine, Angew. Chem. Int. Ed. Engl. 49 (2010) 3280-3294.

[7] P.Y. Lim, R.S. Liu, P.L. She, C.F. Hung, H.C. Shih, Synthesis of Ag nanospheres particles in ethylene glycol by electrochemical-assisted polyol process, Chem. Phys. Lett. 420 (2006) 304-308.

[8] K.E. Korte, S.E. Skrabalak, Y. Xia, Rapid synthesis of silver nanowires through a CuCl- or $\mathrm{CuCl}_{2}$ - mediated polyol process, J. Mater. Chem. 18(4) (2008) 437-441.

[9] J. Kou, R.S. Varma, Speedy fabrication of diametercontrolled Ag nanowires using glycerol under microwave irradiation conditions, Chem. Commun. 49(7) (2013) 692-694.
[10] T. Yamamoto, H. Yin, Y. Wada, T. Kitamura, T. Sakata, H. Mori, S. Yanagida, Morphology-control in microwave-assisted synthesis of silver particles in aqueous solutions, Bull. Chem. Soc. Jpn. 77(4) (2004) 757-761.

[11] J. Moghimi-Rad, T. Dallali Isfahani, I. Hadi, S. Ghalamdaran, J. Sabbaghzadeh, M. Sharif, Shape-controlled synthesis of silver particles by surfactant selfassembly under ultrasound radiation, Appl. Nanosci. 1 (2011) 27-35.

[12] J.P. Abid, A.W. Wark, P.F. Brevet, H.H. Girault, Preparation of silver nanoparticles in solution from a silver salt by laser irradiation, Chem. Commun. 7(7) (2002) 792-793.

[13] L.C. Courrol, F.R. Oliveira Silva, L. Gomes, A simple method to synthesize silver nanoparticles by photo-reduction, Colloids Surf. A: Physicochem. Eng. Aspects 305 (2007) 54-57.

[14] P.K. Sahoo, S.S Kamal, T. Jagadeesh, B. Sreedhar, A.K. Singh, S.K. Srivastava, Synthesis of silver nanoparticles using facile wet chemical route, Def. Sci. J. 59 (2009) 447-455.

[15] Albin Antony, S. Pramodini, P. Poornesh, I.V. Kityk, A.O. Fedorchuk, Ganesh Sanjeev, Influence of electron beam irradiation on nonlinear optical properties of $\mathrm{Al}$ doped $\mathrm{ZnO}$ thin films for optoelectronic device applications in the $\mathrm{CW}$ laser regime, Opt. Mater. 62 (2016) 64-71.

[16] M. Catauro, M. Raucci, F. De Gaetano, A. Marotta, Antibacterial and bioactivesilver-containing $\mathrm{Na}_{2} \mathrm{O} \cdot \mathrm{CaO} \cdot 2 \mathrm{SiO}_{2}$ glass prepared by sol-gel method, J. Mater. Sci.: Mater. Med. 15(7) (2004) 831-837.

[17] Ali Mirzaei, Kamal Janghorban, Babak Hashemi, Maryam Bonyani, Salvatore Gianluca Leonardi, Giovanni Neri, Characterization and optical studies of PVPcapped silver nanoparticles, J. Nanostruct. Chem. 7 (2017) 37-46.

[18] Z. Zhang, V.J. Li, Synthesis and characterization of silver nanoparticles by a sonochemical method, Rare Metal Mater. Eng. 41 (2012) 1700-1705.

[19] Y.K. Mishra, S. Mohapatra, D. Kabiraj, B. Mohanta, N.P. Lalla, et al., Synthesis and characterization of Ag nanoparticles in silica matrix by atom beam sputtering, Scr. Mater. 56 (2007) 629-632.

[20] Z. Zhang., B. Zhao, L. Hu, PVP protective mechanism of ultrafine silver powder synthesized by chemical reduction processes, J. Solid State Chem. 121 (1996) 105-110.

[21] M. Rai, A. Yadav, A. Gade, Silver nanoparticles as a new generation of antimicrobials, Biotech. Adv. 27 (2009) 76-83.

[22] M. Bin Ahmad, J. Jye Lim, K. Shameli, N. Azowa Ibrahim, M.Y. Tay, B. W. Chieng Antibacterial activity of silver bionanocomposites synthesized by chemical reduction route, Chem. Central Jour. 6 (2012) 101-109

[23] Y. Murali Mohan, K. Vimala, V. Thomas, K. Varaprasad, B. Sreedhar, et al. Controlling of silver nanoparticles structure by hydrogel networks, J. Colloid Int. Sci. 342 (2010) 73-82.

[24] S. Amrut, Lanje, J. Satish, Sharma, B. Ramchandra, Pode, Synthesis of silver nanoparticles: a safer alternative to conventional antimicrobial and antibacterial agents, J. Chem. Pharm. Res. 2(3) (2010) 478-483.

[25] M. Abdul Majeed Khan, S. Kumar, M. Ahamed, S.A. Alrokayan, M. Saleh Al Salhi, M. Khan, Structural and thermal studies of silver nanoparticles and electrical transport study of their thin films, Nano. Res. Lett. 6 (2011) 434-411.

[26] J. Prince Richard, I. Kartharinal Punithavathy, S. Johnson Jeyakumar, M. Jothibas, P. Praveen, Effect of morphology in the photocatalytic degradation of methylviolet dye using ZnO nanorods, J. Mater Sci: Mater Electron. 28 (2016) 4025-4034.

[27] Y.P. Venkata Subbaiah, P. Prathap, K.T. Ramakrishna Reddy, Structural, electrical and optical properties of $\mathrm{ZnS}$ films deposited by close-spaced evaporation, Appl. Surf. Sci. 253 (2006) 2409-2415

[28] B.K. Jena, B.K. Mishra, S. Bohidar, Synthesis of branched Ag nanoflowers based on a bioinspired technique: their surface enhanced Raman scattering and antibacterial activity, J. Phys. Chem. 113 (2009) 14753-14758.

[29] M.M. Koebel, L.C. Jones, G.A. Somorjai, Preparation of size-tunable, highly monodisperse PVP-protected Pt-nanoparticles by seed-mediated growth, J. Nanopart. Res. 10 (2008) 1063-1069.

[30] N. Giri, R. Natarajan, S. Gunasekaran, S. Shreemathi, ${ }^{13} \mathrm{C}$ NMR and FTIR spectroscopic study of blend behavior of PVP and nano silver particles, Arch. Appl. Sci. Res. 3 (2011) 624-630.

[31] P. Sivakumar, R. Ramesh, A. Ramanand, S. Ponnusamy, C. Muthamizhchelvan, Synthesis and characterization of $\mathrm{NiFe}_{2} \mathrm{O}_{4}$ nanosheet via polymer assisted coprecipitation method, Mater. Lett. 65 (2011) 483-485.

[32] Y. Gao, P. Jiang, D.F. Liu, H.J. Yuan, X.Q. Yan, et al., Evidence for the monolayer assembly of poly(vinylpyrrolidone) on the surfaces of silver nanowires, J. Phys. Chem. B 108 (2004) 12877-12881.

[33] Y.J. Song, M. Wang, X.Y. Zhang, J.Y. Wu, T. Zhang, Investigation on the role of the molecular weight of polyvinyl pyrrolidone in the shape control of high-yield silver nanospheres and nanowires, Nano. Res. Lett. 9 (2014) 17-24.

[34] M.L. Bastarrachea, W.H. Kao, J.C. Rodrõ Âguez, J.C. Uc, H.V. Torres, A.Â. VilaOrtega, TG/FTIR study on the thermal degradation of poly (vinyl pyrrolidone). J. Therm. Anal. Calorim. 104(2) (2010) 737-742.

[35] N.L. Yong, A. Ahmad, A.W. Mohammad, Synthesis and characterization of silver oxide nanoparticles by a novel method, Int. J. Sci. Eng. Res. 4 (2013) 155-158.

[36] C.N. Baker, S.A. Stocker, D.H. Culver, C. Thornsberry, Comparison of the E test to agar dilution, broth microdilution and agar diffusion susceptibility testing techniques by using a special challenge set of bacteria, J. Clin. Microbiol. 29 (1991) 533-538.

[37] Y. Erfani, A. Rasti, A. Mirsalehian, S. M. Mirafshar, V. Ownegh, E-test versus disk diffusion method in determining multidrug resistant strains of Escherichia coli in urinary tract infection, Afr. J. Microbiol. Res. 5 (2011) 608-611. 